
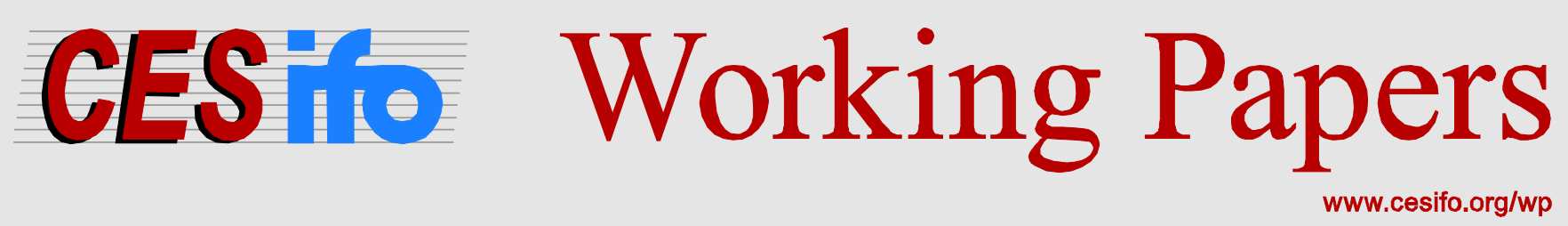

\title{
Inherited Wealth and Demographic Aging
}

\author{
Harun Onder \\ Pierre Pestieau
}

\author{
CESIFO WORKING PAPER NO. 5984 \\ CAtegory 6: Fiscal Policy, Macroeconomics and Growth \\ JULY 2016
}

An electronic version of the paper may be downloaded

- from the SSRN website:

- from the RePEc website:

- from the CESifo website:

wWw.SSRN.com

www.RePEc.org

www.CESifo-group.org/wp

\section{CESifo}




\title{
Inherited Wealth and Demographic Aging
}

\begin{abstract}
The role of inherited wealth in modern economies has increasingly become under scrutiny. This study presents one of the first attempts to shed light on how demographic aging could shape this role. We show that, in the absence of retirement annuities, or for a given level of annuitization, both increasing longevity and decreasing fertility should reduce the inherited share of total wealth in a given economy. Thus, aging is not likely to explain a recent surge in this share in some advanced economies. Shrinking retirement annuities, however, could offset and potentially reverse these effects. We also show that aging could increase the size of individual bequests visà-vis real wages. However, these bequests will be more unequally distributed if aging is driven by a drop in fertility. In comparison, the effect of increasing longevity on their distribution in non-monotonic.
\end{abstract}

JEL-Codes: D140, D310, D640, D910, E210, H550, J110.

Keywords: inherited wealth, inheritance, aging, inequality, social security.

Harun Onder

Macroeconomics and Fiscal Management

Global Practice / The World Bank

Washington / DC / USA

honder@worldbank.org
Pierre Pestieau

Department of Economics

University of Liege

Belgium - 4000 Liege

p.pestieau@ulg.ac.be

June 28, 2016

We are grateful for financial support from Research Support Budget (RSB) of the World Bank's Development Research Group (DEC), which made this research possible. We would like to thank Shiva Makki, two anonymous referees in RSB, Tito Cordella, Fernando L. Hernandez, Swati Ghosh, and the seminar participants at the World Bank for useful comments and suggestions. 


\section{Introduction}

An important premise of the modern capitalism is the idea that anyone, regardless of her parent's wealth, can become rich with the right entrepreneurial skills. A recent surge of self-made billionaires is often considered to be the proof of this. For instance, Kaplan and Rauh (2013) report that among the Americans who made it to the Forbes 400 list, which provides a list of the wealthiest people ranked by net worth, the share of those who grew up wealthy fell from 60 percent to 32 percent between 1982 and 2011. There seems to go the age of aristocracy, inherited wealth, and privilege. But, does it?

Notwithstanding the observation above, the role of inherited wealth is on the rise in a number of advanced economies. Piketty and Zucman (2014) show that although the inherited share of total wealth decreased steadily from the beginning of the 20th century until 1970s in Europe (Figure 1 for France, UK and Germany), it began to increase again after that, a trend that has continued till now. Accordingly, the earlier reduction was driven by wars in the first half of the century, which impoverished the population across the board. Consequently, those who died between 1950-1960 were reported to be the least wealthy generation (measured at the time of death) in the 20th century. The increase in the inherited share of total wealth, on the other hand, stemmed from increasing inter vivos gifts. Although it is not clear why such gifts started increasing, Piketty and Zucman (2014) suggest that ever longer lives may have induced parents to transfer a portion of inheritance sooner to help their offspring. We can infer from this argument that the total bequeathed wealth (both in the form of inheritance and inter vivos gifts) have also increased as a response to longer lives, which is the main motivation for our discussion here.

How exactly does aging of a population affect the size and distribution of its inherited wealth? It is well known that decreasing mortality and fertility rates, both of which leads to an increase in average age in a society, have lead to dramatic changes in demographic structure of societies, especially in high income countries, in recent decades. Figure 2 shows the survival curves from 1950 to 2010. For instance, a 60 years old person could expect to live about 17 more years in 1950, and that has increased to 23 by now. In the meantime, fertility rate fell from about 3 children per woman to 1.8 children. In this paper, we formalize the ideas summarized in a companion paper of ours, Onder and Pestieau (2016a), to study the effects of these changes on the role of inheritance in modern societies in a somewhat systematic manner ${ }^{1}$.

In particular, we are interested in shedding light on effects of a decrease in fertility and of an increase in longevity on three indicators that define the size and distribution of inherited wealth, albeit in an imperfect manner. These are:

\footnotetext{
${ }^{1}$ See also Weil (1996)
} 
Figure 1: The share of inherited wealth in total private wealth, 1900-2010

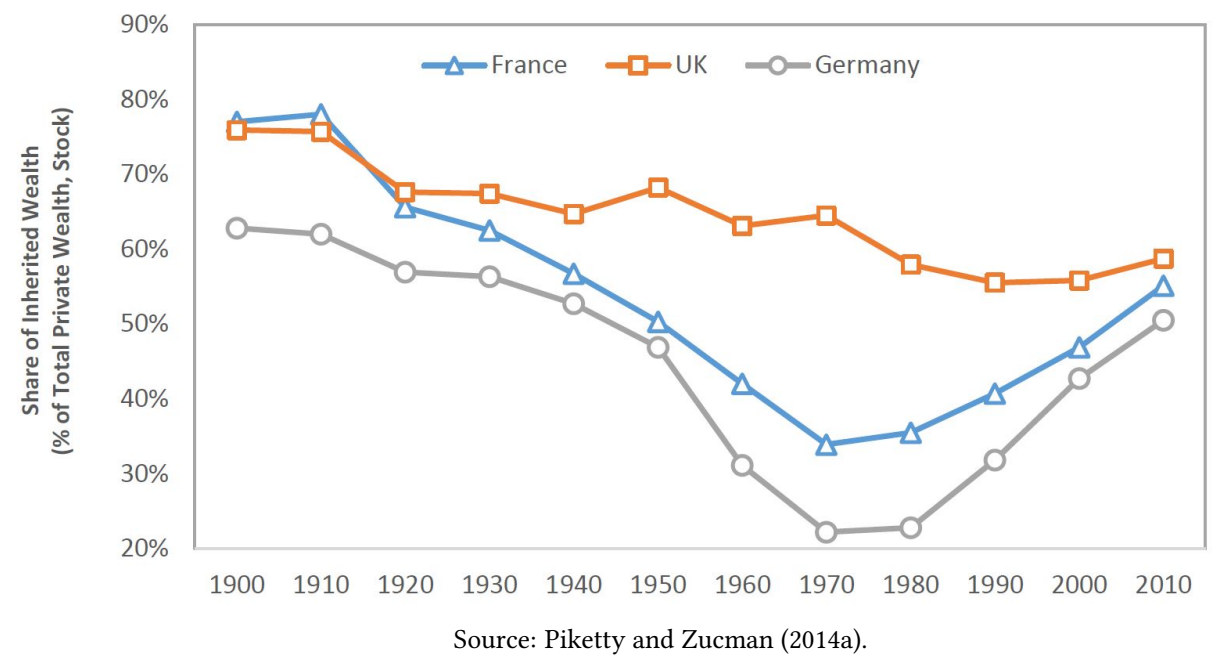

1. Inherited share of total wealth (ISW), which indicates the aggregate role of inheritance,

2. Inheritance to real wage ratio (RIW), which denotes the size of a single bequest,

3. Inherited wealth inequality (IWI), which characterizes the distribution of inheritance.

In order to investigate the effects of aging on these three indicators, we adopt a simple two-period OLG model where individuals save for retirement and for the joy of bequeathing. As parts of these savings are not annuitized, the model also features accidental bequests in addition to altruistic bequests. Using this framework we find that, as opposed to the implication made by Piketty and Zucman (2014), aging in either form, a decrease in fertility or an increase in longevity, is not likely to explain the U-shaped pattern in the inherited share of total wealth in advanced economies. Both types of aging are expected to reduce the ISW. This is primarily because intentional bequests fall following a decrease in fertility, and although individual accidental bequests become larger with decreasing mortality, they also become less frequent, which dominates the effect on the size.

Our results also suggest an alternative mechanism that could generate such a U-shaped pattern of the ISW after the Second World War: the rise and fall of retirement annuities. In many high income countries, public and private defined benefits systems took up after the second world war and the benefits provided by these systems increased steadily for several decades. Our simulations show that, other things being equal, an increase in such annuitization could lead to a decrease in the ISW. Interestingly, however, the annuitization trend was reversed towards the end of the century following a decline in public pension benefits and a progressive shift from defined benefit to defined contribution pensions. Thus, in theory, the rebound of the ISW could be driven by such a progressive abandonment of annuitized retirement savings. 
Figure 2: Evolution of survival in high income countries, 1950-2010

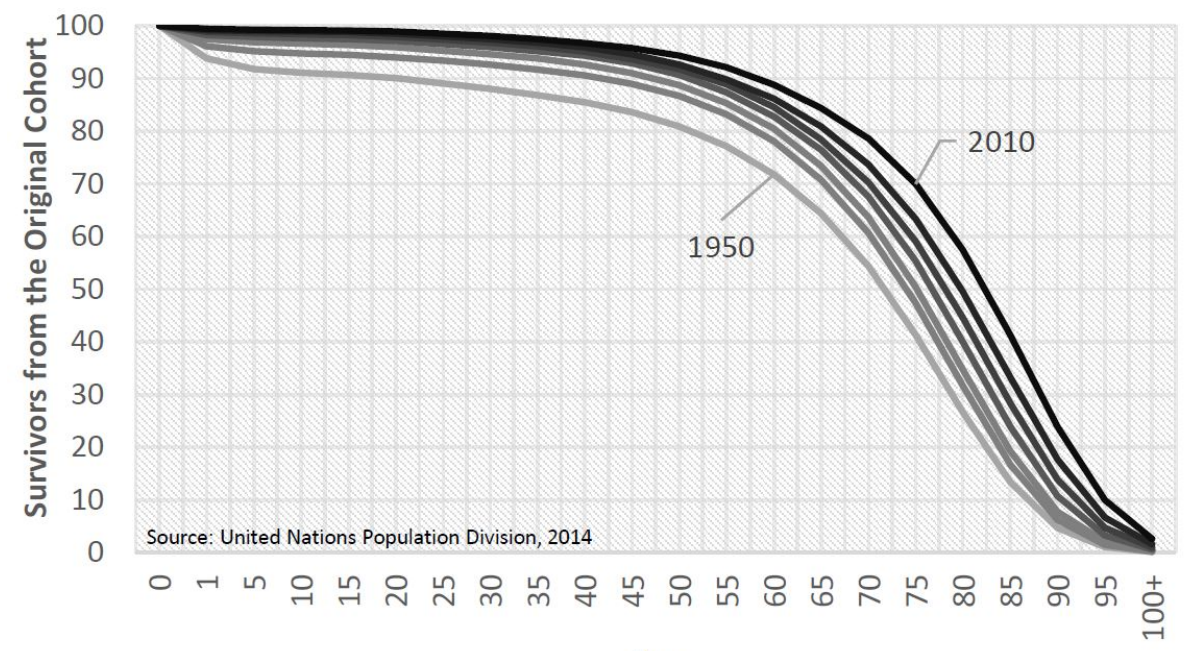

Age

Before proceeding two observations are in order. First, several authors have challenged the findings of Piketty and Zucman as to the recent upsurge of inherited wealth. Wolff (2015) notes that such upsurge does not apply to the US. Rognlie (2015) on the other hand join many other critiques to show that real estate wealth is not properly measured in Piketty's work. Second, the recent decline in the annuitization of retirement saving comes from two factors. There is the widespread decline in individual public pension benefits that is due to the increase in the number of retirees and to the governments' budgetary difficulties. For example, in most European countries one observes a sharp decline in the replacement ratio in public pensions. This is due to the fact that they apply indexation rules for pensions that do not fully reflect a 1:1 relationship with nominal wage increases. (See on this European Commission, 2015). Further in private pensions, either mandatory or voluntary there is a trend towards defined contribution formulas along with a payout in capital instead of in annuities. Such a trend can be explained by the desire of pension funds to reduce financial and longevity risks and by the preference of retirees towards cashing in assets accumulated in defined contribution pension plans. (See Antonin, 2008 and Munnell et al., 2014).

This paper continues with a discussion on how aging affects bequeathing at individual level in the next section. In section 3 we consider the effects of aging on economy-wide indicators of inherited wealth with and without annuitization. The last section provides some concluding remarks. 


\section{A Simple Model with Annuities}

We use a simple two-period overlapping generations model to show our points. An individual who belongs to generation $t$ can live for two periods: $t$ and $t+1$. All individuals live a healthy life in the first period of their lifetimes, however, only a portion $\pi \in[0,1]$ of them can survive to live in the second period. We assume that the ex-ante probability of survival, $\pi$, is identical for all individuals regardless of their income and wealth. ${ }^{2}$

In the first period, each individual works and earns a wage $w_{t}$ and receives a bequest from her parent $b_{t}$. A portion of these is used to finance the first-period consumption, $c_{t}$, and the rest is saved for two reasons: leaving bequests for own children $\left(x_{t}\right)$ and financing a possible second period consumption, where the individual is assumed not to work for simplicity. The consumption oriented savings comprise a predetermined component in the form of annuities $a_{t}$ and a voluntary component $s_{t}$, which is not annuitized. The bequest is motivated as a "warm glow" giving that is based on some internal feeling of virtue arising form sacrifice in helping one's children or by the desire of controlling their life. ${ }^{3}$

If the individual lives over two periods successfully, then the second period consumption is given by $d_{t+1}=R_{t+1}\left(s_{t}+\frac{a_{t}}{\pi}\right)$, where the second component in the brackets shows the annuities adjusted by the survival rate, and her bequest per child is given by $b_{t+1}=R_{t+1} x_{t} / n$, where $R_{t+1}$ is the interest earnings on savings and $n$ is the number of children. In comparison, if the individual dies at the end of the first period, all her savings will "accidentally" be inherited by her children, $b_{t+1}^{*}=R_{t+1}\left(s_{t}+x_{t}\right) / n$ and her claims to annuity will be reflected in other beneficiaries annuities.

The utility maximization problem of an individual is given by:

$$
\begin{gathered}
\max _{s, x} U_{t}=w_{t}+\beta_{t}-s_{t}-x_{t}-a_{t}+\pi\left[u\left(d_{t+1}\right)+n \gamma u\left(b_{t+1}\right)\right]+(1-\pi) n \gamma u\left(b_{t+1}^{*}\right) \\
\text { s.t. } \quad d_{t+1}=R_{t+1}\left(s_{t}+\frac{a_{t}}{\pi}\right), b_{t+1}=\frac{R_{t+1} x_{t}}{n}, b_{t+1}^{*}=\frac{R_{t+1}\left(s_{t}+x_{t}\right)}{n}
\end{gathered}
$$

where $\gamma \in[0,1]$ shows the relative utility weight of bequests in comparison to consumption, and $\beta \in\left\{b_{t}, b_{t}^{*}\right\}$. The first order conditions of this problem are given by:

$$
1=\pi u^{\prime}\left(d_{t+1}\right) R_{t+1}+(1-\pi) \gamma u^{\prime}\left(b_{t+1}^{*}\right) R_{t+1}
$$

\footnotetext{
${ }^{2}$ See Lefebvre et al (2013) for an analysis on income-differentiated mortality.

${ }^{3}$ See Androni (1990) for this.
} 


$$
1=\pi \gamma u^{\prime}\left(b_{t+1}\right) R_{t+1}+(1-\pi) \gamma u^{\prime}\left(b_{t+1}^{*}\right) R_{t+1}
$$

and the following equilibrium association between consumption and bequest motives:

$$
u^{\prime}\left(d_{t+1}\right)=\gamma u^{\prime}\left(b_{t+1}\right)
$$

Note that the overall utility is of quasi-linear form when sub-utility functions are non-linear in second period consumption and bequests. This assumption helps us prevent divergence among dynasties by breaking the link between successive bequests, i.e. the optimal bequest chosen by an individual for her offspring is independent of the bequest she receives. Thus, there is a stable number of individual types in the economy at any given time: the offspring of those who die prematurely and leave a large bequest in intentional and accidental form, i.e. $\beta_{t}=b_{t}^{*}$, and the offspring of those who enjoy a long life span and leave only intentional bequests, i.e. $\beta_{t}=b_{t}$. Without this assumption, there would be an explosive number of individual types including a dynasty where all ancestors happened to die prematurely, another dynasty where all ancestors enjoyed complete life spans, and all combinations in between these two. This is undoubtedly a strong assumption on which we come back in the concluding comments. Other less severe assumptions are that annuities are actuarily fair and that, in spite of aging, the expected length of activity is constant.

We are primarily interested in showing how changes in fertility and survival rates, $n$ and $\pi$, respectively, affect two commonly used indicators of wealth accumulation. These are the share of inherited wealth in total wealth (ISW) and inheritance to wage ratio (RIW). Furthermore, we look at the effect of aging on inherited wealth inequality (IWI). In our simple model, these can formally be defined as follows:

$$
\text { Inherited share of total wealth }(I S W): \quad \Psi_{t+1}=\frac{(1-\pi) s_{t}+x_{t}}{s_{t}+a_{t}+x_{t}},
$$

$$
\text { Planned inheritance to wage ratio }(R I W-\text { intentional }): \quad \Omega_{\text {int }, t+1}=\frac{b_{t+1}}{w_{t+1}},
$$

$$
\begin{gathered}
\text { Accidental inheritance to wage ratio }(R I W-\text { accidental }): \quad \Omega_{a c c, t+1}=\frac{b_{t+1}^{*}-b_{t+1}}{w_{t+1}} \\
\text { Inherited wealth inequality }(I W I): \quad \Phi_{t}=\frac{\sqrt{V\left(\omega_{t}\right)}}{\bar{\omega}_{t}}
\end{gathered}
$$


where $\omega_{t} \in\left\{b_{t}, b_{t}^{*}\right\}$ denote different types of bequest, $V(\omega)$ denotes the variance of bequests, and $\bar{\omega}_{t}=\pi b_{t}+(1-\pi) b_{t}^{*}$ shows the average size of bequest. Therefore, $\Phi_{t}$ is the coefficient of variation, defined for bequests. We separate the inherited wealth to wage ratio into two components: the intentionally inherited wealth to wage ratio $\left(\Omega_{\text {int }}\right)$, which applies to those whose parents lived for a full life span, and the accidentally inherited wealth to wage ratio $\left(\Omega_{a c c}\right)$, which applies to those whose parents dies prematurely in addition to the intentional bequests. Note that whereas the inherited share of total wealth is an economy-side aggregate indicator, the inheritance to wage ratio focuses on the inheritance received by a given individual in order to facilitate a discussion on inequality among individuals, thus it is not to be confused with the aggregate inheritance in the economy.

We next investigate the equilibrium behavior by imposing specific functional forms to subutility and production functions.

\section{A Stylized Specification}

We now solve the problem characterized in the previous section by assuming logarithmic subutility functions and Cobb-Douglas production function. These help us to obtain some analytical insights and perform numerical simulations when there is no analytical solution. It also helps us to guarantee the existence of a unique and stable steady-state. With logarithmic preferences, the utility maximization problem of an individual is now given by:

$$
\max _{s, x} U_{t}=w_{t}+\beta_{t}-s_{t}-x_{t}-a_{t}+\pi\left[\log \left(d_{t+1}\right)+n \gamma \log \left(b_{t+1}\right)\right]+(1-\pi) n \gamma \log \left(b_{t+1}^{*}\right)
$$

The first order conditions with respect to $s_{t}$ and $x_{t}$, respectively, are as follows:

$$
\begin{gathered}
0=-1+\frac{\pi}{s_{t}+\frac{a_{t}}{\pi}}+\frac{(1-\pi) n \gamma}{s_{t}+x_{t}} \\
0=-1+\frac{\pi n \gamma}{x_{t}}+\frac{(1-\pi) n \gamma}{s_{t}+x_{t}}
\end{gathered}
$$

The first condition equalizes the marginal disutility from saving in the first period to the expected marginal utility of saving in the second period. Thus, the individual increases her savings until the expected sum of these utilities is equal to the opportunity cost of saving. The same idea applies to the voluntary bequests, $x$. Combining the two first order conditions above, we obtain the following relationship:

$$
x_{t}=n \gamma\left(s_{t}+\frac{a_{t}}{\pi}\right)
$$


which is a special case of (4).

Intuitively, voluntary savings for future consumption and intentional bequests should yield the same marginal utilities after adjusting for the number of offspring and expected annuity benefits. The motion of capital is described as:

$$
n k_{t+1}=s_{t}+a_{t}+x_{t}=s_{t}+a_{t}+n \gamma\left(s_{t}+\frac{a_{t}}{\pi}\right)
$$

where $k$ denotes capital per worker. Using a Cobb-Douglas production function, $y=k^{\alpha}$, we get the following definitions for the equilibrium interest rates and wages:

$$
\begin{gathered}
R_{t+1}=\alpha\left[\frac{s_{t}+a_{t}}{n}+\gamma\left(s_{t}+\frac{a_{t}}{\pi}\right)\right]^{\alpha-1} \\
w_{t+1}=(1-\alpha)\left[\frac{s_{t}+a_{t}}{n}+\gamma\left(s_{t}+\frac{a_{t}}{\pi}\right)\right]^{\alpha}
\end{gathered}
$$

Note that we assume that capital is assumed to depreciate completely after each period. Although this assumption arises from convenience, it is not unrealistic considering the fact that a period denotes several decades in calendar.

\subsection{A Case Without Annuities}

Note that when $a_{t}=0$, i.e. we shut down the annuity channel, all savings are bequeathable, and the optimal $x_{t}$ and $s_{t}$ become proportional in equation 12. Although this observation is not specific to logarithmic utility form, it proves to be an important property. ${ }^{4}$

In order to assess how aging may affect the inherited share of aggregate wealth in our stylized specification with quasi-linear utility, logarithmic sub-utilities, and Cobb-Douglas production, we use the definition 5 and set $a_{t}=0$. Note that when the relationship between $s$ and $x$ is defined with (12), the $\Psi$ is reduced to

$$
\Psi_{t}=\frac{(1-\pi)+n \gamma}{1+n \gamma}
$$

from which $\partial \Psi / \partial \pi<0$ and $-\partial \Psi / \partial n<0$ follow through. We summarize this result in the following proposition.

Proposition 1. In the absence of annuities, the inherited share of aggregate wealth decreases with an increase in longevity (decrease in mortality) or a decrease in fertility.

This is the most important and rather robust result of our analysis. A decrease in fertility or an increase in longevity have a depressive effect on the relative importance of inheritance in

\footnotetext{
${ }^{4}$ More generally, the proportionality between $x_{t}$ and $s_{t}$ can also be generated by any sub-utility function of the Constant Relative Risk Aversion (CRRA) form.
} 
wealth accumulation. Thus, this finding result does not support Piketty and Zucman's argument in this case.

Similarly, in order to assess how aging changes the size of inheritance vis-a-vis real wages, we solve for equilibrium $R_{t+1}$ and $w_{t+1}$ by using the relationship (12), and plugging in the definitions defined by equations (6) and (7), to get the following:

$$
\Omega_{i n t, t+1}=\frac{\alpha n \gamma}{(1-\alpha)(1+n \gamma)} \quad \text { and } \quad \Omega_{a c c, t+1}=\frac{\alpha}{(1-\alpha)(1+n \gamma)}
$$

from which $\partial \Omega_{i n t} / \partial \pi=\partial \Omega_{a c c} / \partial \pi=0, \partial \Omega_{i n t} / \partial n>0$ and $\partial \Omega_{a c c} / \partial n<0$ follow through.

Proposition 2. A decrease in fertility leads to a reduction in the intentional bequest to wage ratio and an increase in the accidental bequest to wage ratio. Both ratios are unaffected by changes in longevity.

Finally, we consider the effect of aging on inequality of inherited wealth. Even though this paper is not properly about wealth inequality, it might be useful to use our simple model with $a=0$ to assess the impact of aging on the distribution of inherited wealth. In this case, we know that $x=n \gamma s$, and there are two levels of inherited wealth in the society: those of the children whose parent survives $\left(\omega_{1}\right)$ and those of the children whose parent did not survive $\left(\omega_{2}\right)$. The average wealth is, then, defined as: $\bar{\omega}=\pi \omega_{1}+(1-\pi) \omega_{2}$, which is used to define the variance of wealth as:

$$
V(\omega)=\frac{R^{2}}{n^{2}} s^{2} \pi(1-\pi) .
$$

We will use the coefficient of variation as a measure of inequality $(\Phi)$ :

$$
\Phi=\frac{\sqrt{V(\omega)}}{\bar{\omega}}=\frac{\sqrt{\pi(1-\pi)}}{n \gamma+(1-\pi)} .
$$

which lends itself to study the effect of $n$ and $\pi$ on it.

$$
\frac{d \Phi}{d n}<0 ; \frac{d \Phi}{d \pi} \gtrless 0 \Leftrightarrow \pi \lessgtr 1 / 2
$$

In words, we observe that aging has a dis-equalizing effect for any value of $n$ and for $\pi<1 / 2$. This result is summarized in the following proposition.

Proposition 3. A decrease in fertility increases the inequality of inherited wealth in the absence of annuities. In comparison, starting from low levels $(\pi<1 / 2)$, an increase in longevity first increases this inequality and then, for relatively high levels of longevity $(\pi>1 / 2)$, decreases it. 
Note that this result depends on how we measure inequality. Using a variance based indicator (coefficient of variation) to measure the dispersion, as it is known commonly, implies that the highest variance is reached when the probability of survival is equal to 0.5 .

Next, we will reconsider the effects of different types of aging on the indicators of inherited wealth when annuities are present.

\subsection{The Case with Annuities}

We have just seen that without annuities aging has a clear depressing effect on inherited wealth whether it arises from declining fertility or increasing longevity. We now explore the alternative idea that an increase in the share of inherited wealth could be driven by a decline in annuitized retirement savings. To investigate this when $a_{t}>0$ we have to resort to numerical simulations as we cannot get analytical solutions for our variables of interest even though the model at hand is extremely simple.

Abstaining from calibrating a simplistic model to match the complex nature of actual data, we choose common values from literature to perform the numerical simulations. These include parameters $\alpha=0.3$ and $\gamma=0.5$ for all cases; and fixed variable values $\pi=0.8$ in fertility related simulations, $n=1.5$ in longevity related simulations, and $a=0.05$ when investigating the effects of aging on inheritance to real wage ratios. The amount of annuities denoted by a is exogenous. It is supposed to comprise both public pensions and mandatory annuities. Implicitly we assume fully funded pensions. Introducing pay as you go pensions would not change the nature of results. Our findings from simulations are discussed below.

\section{Voluntary Savings $(s)$}

Figure 3 shows the effects of annuities, fertility, and longevity on equilibrium savings that are undertaken on a voluntary basis. The contours denote the iso-savings combinations, and as the shades shift from darker to lighter tones, the voluntary savings increase.

An increase in annuities decreases voluntary savings, $\frac{\partial s}{\partial a}<0$. From an individual perspective, annuities and voluntary savings are substitutes in financing consumption in the second period of life. Thus, given the survival probability $\pi$, an increase in annuities decreases the expected marginal utility from saving an additional dollar voluntarily.

A decrease in fertility rates decreases voluntary savings, $-\frac{\partial s}{\partial n}<0$. From the first order condition (10), it is clear that an increase in fertility rate $n$ increases the marginal utility of voluntary savings $s$ from the accidental bequest channel (last term on the right hand side). Therefore, ceteris paribus, an increase in $n$ leads to an increase in $s$. However, there is a stronger motive for additional savings in this case, and that is the drive to leave bequests directly/intentionally. Having more 
Figure 3: The impact of changes in longevity, fertility, and annuity on voluntary savings
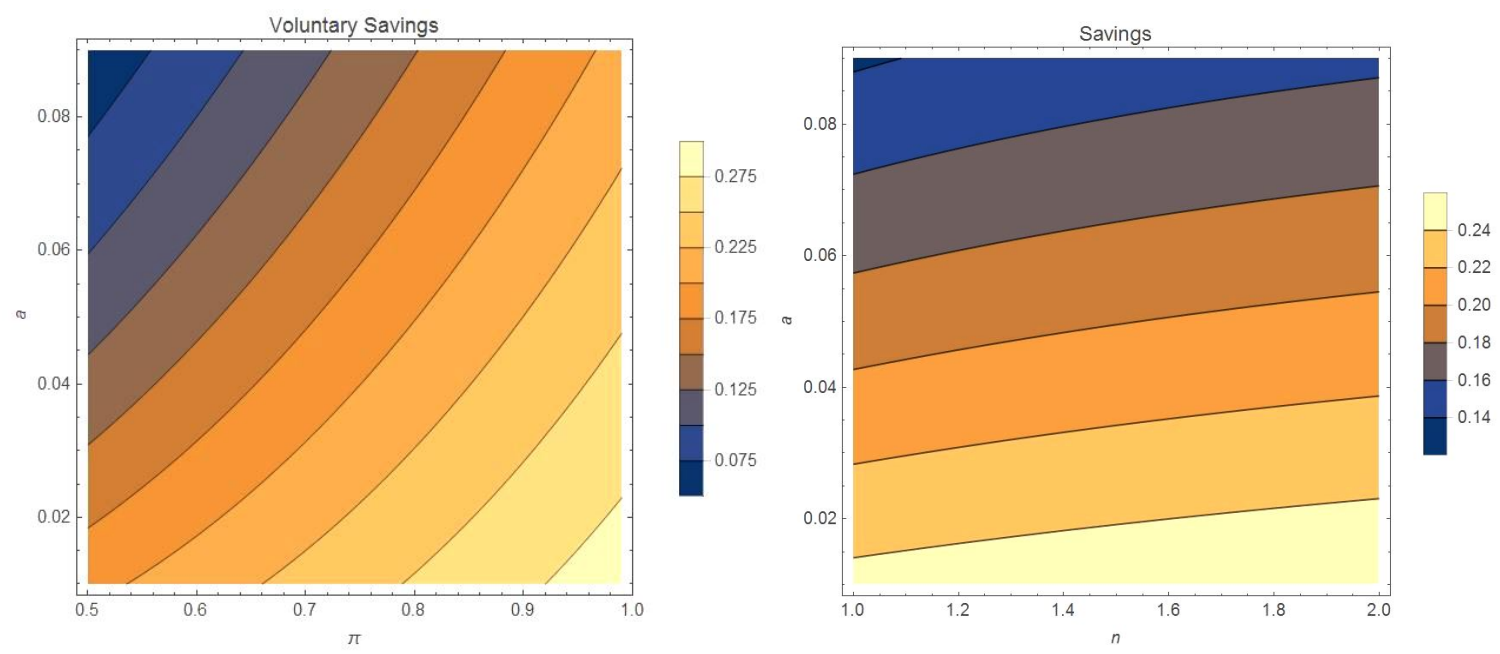

Notes: Horizontal axis shows the mortality rate $(\pi)$ in the left panel and fertility rate $(n)$ in the right panel. In both cases the vertical axes show the annuity values $(a)$. The contour curves show the iso-savings values, and a move from dark blue to light yellow denotes an increase in voluntary savings.

children increases the bequest related savings $x$ more than it does the voluntary savings $s$, as children benefit from the latter probabilistically. This is clear from both the first order condition (11) and the equilibrium relationship between $x$ and $s$, as described in (12).

An increase in longevity increases voluntary savings, $\frac{\partial s}{\partial \pi}>0$. This occurs as a combined result of three factors. First, consumption needs in the second period of life becomes more likely, which has a first order effect on savings. Second, for a given level of $a$, expected annuities $\frac{a}{\pi}$ decrease with $\pi$. To compensate for this, and prevent a substantial loss in second period consumption, the voluntary savings need to be increased. Third, with higher $\pi$, accidental bequests become less likely, therefore the expected marginal utility from leaving an accidental bequest becomes smaller. The last negative effect counteracts the previous positive ones' however, in the end, the former effects dominate and voluntary savings increase in net terms.

\section{The inherited share of total wealth $(\Psi)$}

Figure 4 shows the effects of annuities, fertility, and longevity on the inherited share of aggregate wealth. The contours denote the iso- $\Psi$ combinations, and as the shades shift from darker to lighter tones, the inherited share of total wealth increases.

An increase in annuities decreases the inherited share of total wealth, $\frac{\partial \Psi}{\partial a}>0$. We discussed above that $s$ decreases when $a$ increases. In comparison, $a$ does not have a first order effect on $x$, as we can see from the first order condition 11. Rewriting the inherited share of wealth 
Figure 4: The impact of changes in longevity, fertility, and annuity on inherited share of wealth (ISW)
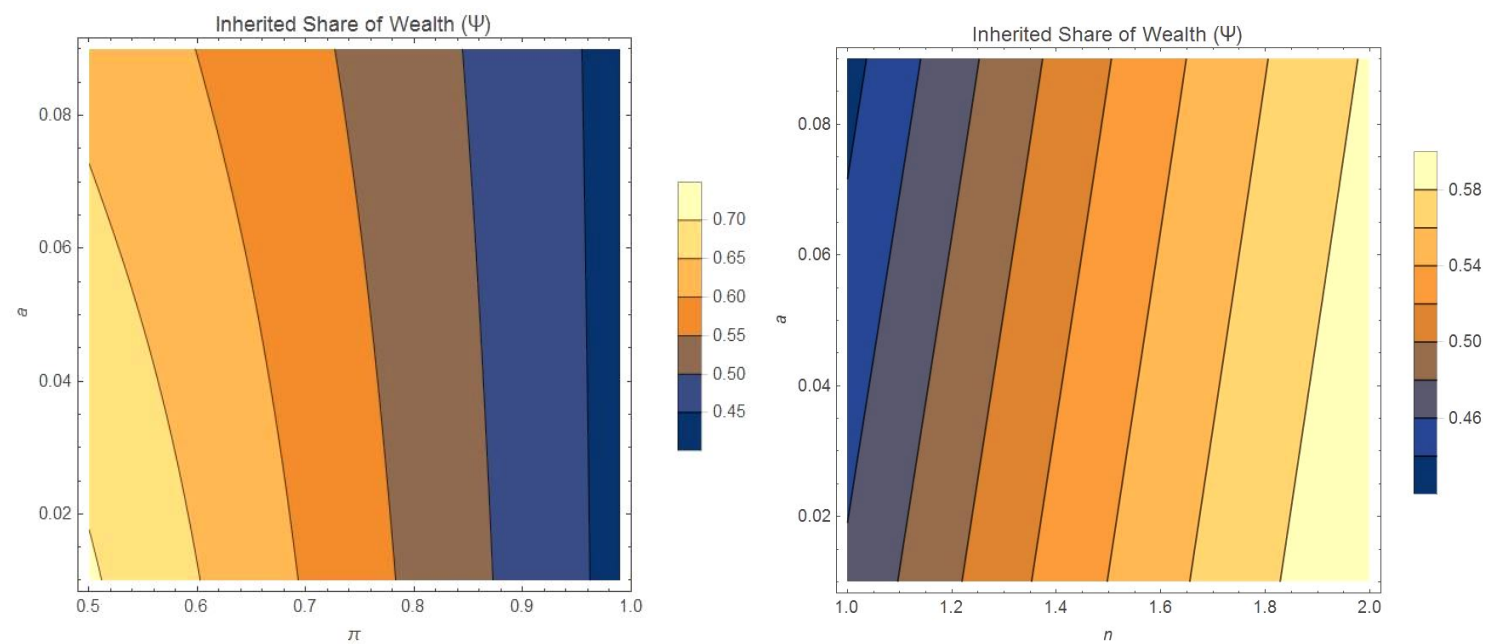

Notes: Horizontal axis shows the mortality rate $(\pi)$ in the left panel and fertility rate $(n)$ in the right panel. In both cases the vertical axes show the annuity values $(a)$. The contour curves show the iso-ISW values, and a move from dark blue to light yellow denotes an increase in the ISW.

from equation 5 as $\Psi_{t}=\frac{(1-\pi)+\frac{x_{t}}{s_{t}}}{1+\frac{x_{t}}{s_{t}}}$, it is clear that the inherited share of wealth increases when $x$ moves little while $s$ becomes smaller in a more pronounced manner. Thus, when $a$ increases, $\Psi$ decreases. This is intuitive as when inheritable savings are replaced by annuities, survivors benefit more from the death of their cohort members, and the offspring of the deceased benefit less. Therefore, the accidentally inherited wealth is smaller. Such an increasing trend in annuities was indeed observed in the post-war era in advanced economies, where pensions coverage with defined benefits increased rapidly. Thus, this result suggests that an increase and a subsequent decrease in annuitization could theoretically explain the U-shaped pattern of inherited share of total wealth observed within the last half-century.

A decrease in fertility rates decrease the inherited share of total wealth, $-\frac{\partial \Psi}{\partial n}<0$. Changes in fertility mainly affect the ISW through intentional bequests. We discussed above that, when $n$ increases, so does $s$ through an indirect channel of accidental bequests. In comparison, having more children increases the bequest related savings $x$ more than it does the voluntary savings $s$, as children benefit from the latter probabilistically. This is clear from both the first order condition (11) and the equilibrium relationship between $x$ and $s$, as described in (12). Rewriting the inherited share of wealth from equation 5 as $\Psi_{t}=\frac{(1-\pi)+\frac{x_{t}}{s_{t}}}{1+\frac{x_{t}}{s_{t}}}$, it is clear that the inherited share of wealth increases when $x$ grows faster than $s$. Thus, when $n$ decreases $\Psi$ also decreases.

An increase in longevity decreases the inherited share of total wealth, $\frac{\partial \Psi}{\partial \pi}<0$. The effect of mortality on ISW is manifested through both intentional and accidental bequests. Other things being equal, the higher the intentional bequests vis a vis the voluntary savings, the higher the 
ISW. Similarly, the higher the mortality, the higher the ISW. To see this, note that, like in the previous case, we can rewrite the inherited share of wealth from equation 5 as $\Psi_{t}=\frac{(1-\pi)+\frac{x_{t}}{s_{t}}}{1+\frac{x_{t}}{s_{t}}}$. Also remember that $x_{t}=n \gamma\left(s_{t}+\frac{a_{t}}{\pi}\right)$ in equilibrium by equation 12 , thus $\frac{\partial x_{t}}{\partial \pi}=n \gamma\left(\frac{\partial s_{t}}{\partial \pi}-\frac{a_{t}}{\pi^{2}}\right)<\frac{\partial s_{t}}{\partial \pi}$ for relatively small population growth rates. Therefore, $\frac{x_{t}}{s_{t}}$ ratio decreases with higher survival probabilities. Other things being equal, this would lead to a decrease in $\Psi$ by itself. In addition, there is also a direct reduction in the numerator as $\pi$ increases. Overall, the numerator in $\Psi_{t}$ decreases faster with high $\pi$ than the denominator. Intuitively, an increase in longevity boosts the wealth accumulation. However, most of this adjustment comes from voluntary savings, which leads to less frequent accidental bequests. As a result, bequests grows less than proportionately in comparison to wealth accumulation.

\section{Inheritance to Wage Ratios $(\Omega)$ :}

This indicator concerns the size of accidental and/or intentional bequests received by a single child in comparison to her real wage. Figure 5 shows the effects of changes in fertility and longevity on the size of intentional and accidental bequests relative to real wages.

A decrease in fertility rate increases the accidental bequest to wage ratio, $-\frac{\partial \Omega_{a c c}}{\partial n}>0$. As accidental bequests are the savings that were intended for the parent's old age consumption but split among the children after the parent's early death, a decrease in number of children has a direct positive effect on how much each child receives. This can be seen by the numerator in $\Omega_{a c c, t+1}=\frac{R_{t+1} s_{t} / n}{w_{t+1}}$, which defines the accidental bequests to real wage ratio. In addition, changes in fertility has indirect effects as well. We know that $s$ decreases with lower $n$, which also affect equilibrium $R$ and $w$. Overall, our simulations show that when $n$ decreases, accidental bequest to wage ratio $\Omega_{a c c}$ increases. Intuitively, with fewer offspring, the savings that was meant to be used for consumption is split among fewer individuals, and thus, each one of them receives a larger share when compared to average real wage.

An increase in longevity increases the accidental bequest to wage ratio, $\frac{\partial \Omega_{a c c}}{\partial \pi}>0$. Remember that the accidental bequest received by each offspring is given by $\Omega_{a c c, t+1}=\frac{R_{t+1} s_{t} / n}{w_{t+1}}$. An increase in $\pi$ increases the voluntary savings $s_{t}$ and real wage $w_{t+1}$, while reducing the interest rate $R_{t+1}$. Overall the increase in savings dominate the decrease in interest rate (this can be shown analytically once we admit $\frac{\partial s}{\partial \pi}$ from numerical simulations), and together, they dominate the increase in wages. Thus, the accidental bequest to real wage ratio increases. Intuitively, higher savings lead to relatively less frequent accidental bequests; but since savings have a first order effect on accidental bequests when it occurs and only a second order effect on wages, the bequest to wage ratio increases.

A decrease in fertility rate decreases the intentional bequest to wage ratio, $-\frac{\partial \Omega_{\text {int }}}{\partial n}<0$. By using 
Figure 5: The impact of changes in longevity, fertility on inheritance to wage ratios (RIW)
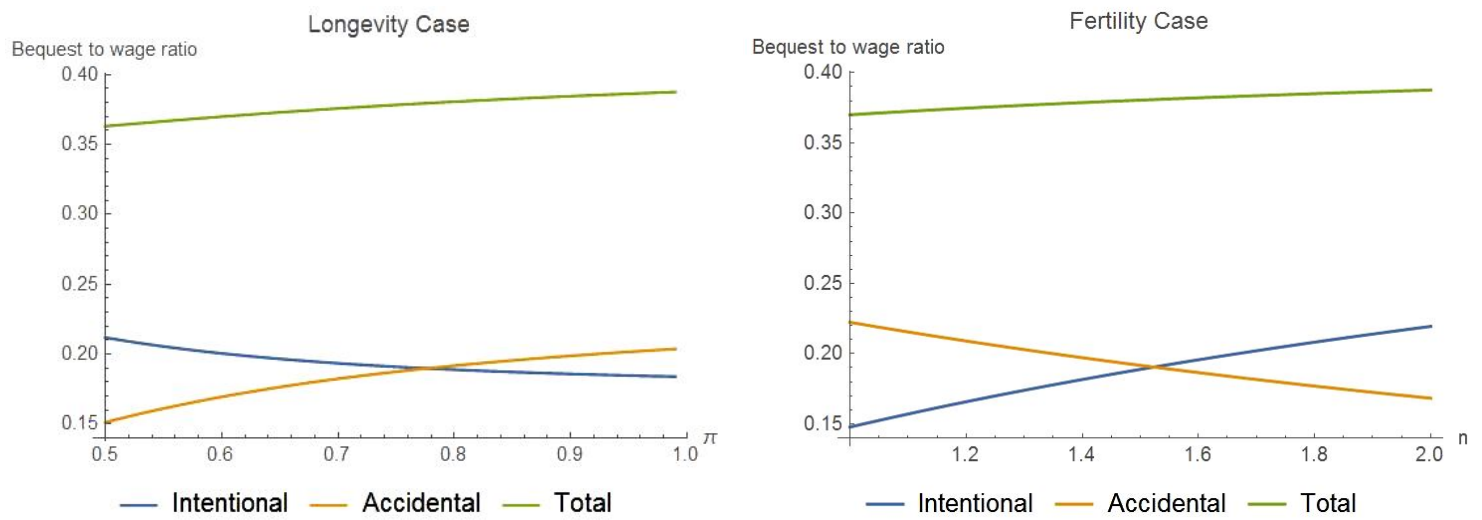

Notes: Horizontal axis shows the mortality rate $(\pi)$ in the left panel and fertility rate $(n)$ in the right panel. In both cases the vertical axes show the RIW.

the equations 6, 14, and 15, we can rewrite the $\Omega_{\text {int }}$ as follows: $\Omega_{\text {int }}=\frac{\alpha}{1-\alpha} \frac{x_{t}}{s_{t}+a_{t}+x_{t}}$. Remember that when $n$ increases, $x_{t}$ grows faster than $s_{t}$ as discussed above. Using this property, it is straightforward to show that $\Omega_{\text {int }}$ and $n$ move in the same direction.

An increase in longevity decreases the intentional bequest to wage ratio, $\frac{\partial \Omega_{i n t}}{\partial \pi}<0$. Remember that $x_{t}=n \gamma\left(s_{t}+\frac{a_{t}}{\pi}\right)$ in equilibrium. Whereas $s_{t}$ increases with higher probability of survival, the received annuities decrease with it. Thus, $x$ increases by less than $s$, and possibly decrease. Using the same definition above, $\Omega_{i n t}=\frac{\alpha}{1-\alpha} \frac{x_{t}}{s_{t}+a_{t}+x_{t}}$, we can see that $\Omega_{i n t}$ could decrease with higher $\pi$ if growth differentials between $x$ and $s$ are substantial.

Although our simulations indicate an increase in total bequest to wage ratio in the case of an increase in longevity and a decrease in it in the case of a decreasing fertility, these results are not robust to alternative parameterizations. Intentional and accidental bequests have opposite signs in both cases; with a variation in the relative taste parameter $\gamma$, either one can dominate the other.

\section{Inequality of inherited wealth $(\Phi)$}

Figure 6 shows the effects of annuities, fertility, and longevity on equilibrium inequality of inheritance. The contours denote the iso-inequality combinations, and as the shades shift from darker to lighter tones, the inequality increases.

An increase in annuitization reduces inheritance inequality, $\frac{\partial \Phi}{\partial a}<0$. Remember that there are two kinds of inheritance in our model, those that are received by children whose parents enjoyed a full life span and those that are received by children whose parents dies prematurely. The difference between the two is accidental bequests. These bequests, in turn, are nothing but the 
Figure 6: The impact of changes in longevity, fertility, and annuity on inherited wealth inequality (IWI)
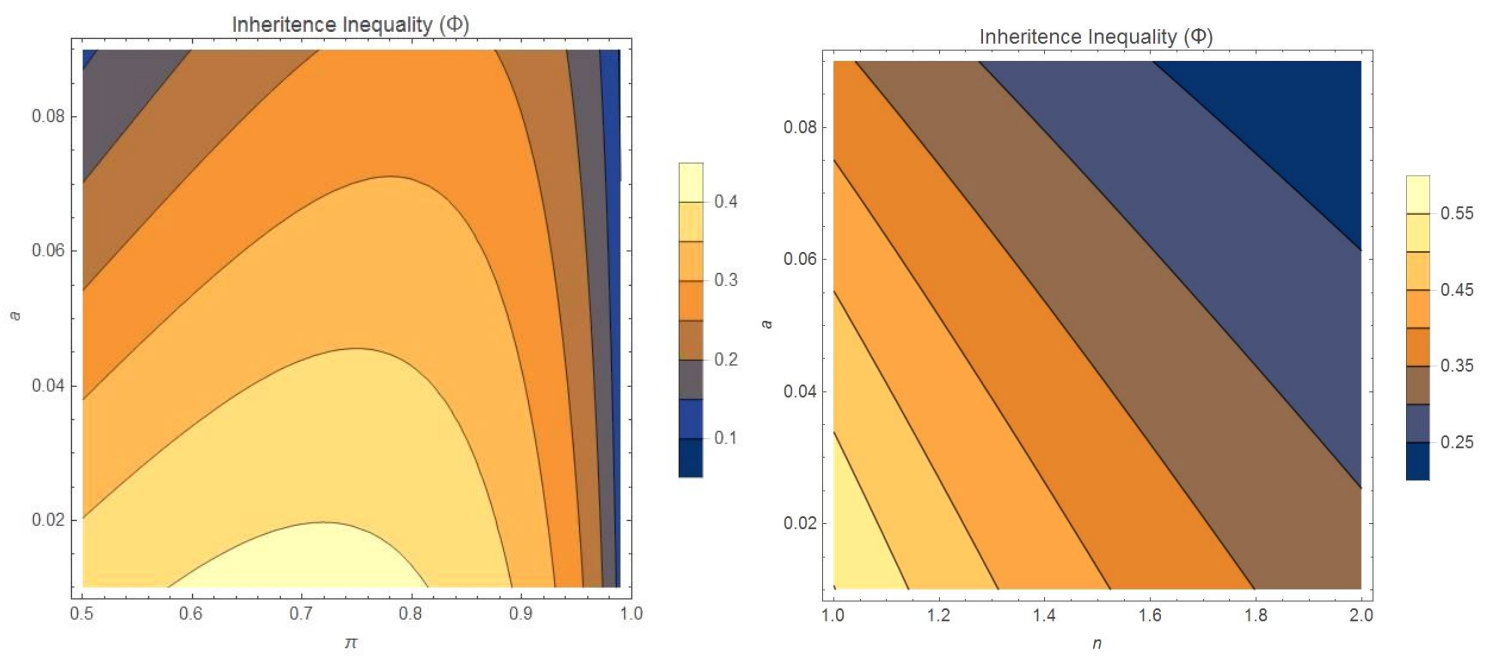

Notes: Horizontal axis shows the mortality rate $(\pi)$ in the left panel and fertility rate $(n)$ in the right panel. In both cases the vertical axes show the annuity values $(a)$. The contour curves show the iso-IWI values, and a move from dark blue to light yellow denotes an increase in the IWI.

voluntary savings that were not consumed by parents who died prematurely, which is depressed by an increase in annuities as we discussed above.

A decrease in fertility increases inheritance inequality, $-\frac{\partial \Phi}{\partial n}<0$. Intuitively, a decrease in fertility reduces both accidental bequests (through voluntary savings) and intentional bequests. However, the impact on the latter is larger. Therefore, although the average inheritance size decreases, the dispersion between the two types inheritances (a large one that comprise both accidental and intentional bequests and a small one with only intentional bequests) increases because the smaller one decreases faster.

The effect of mortality on inequality of inherited wealth is not monotonic, $\frac{d \Phi}{d \pi}<0$ for low $\pi$ and $\frac{d \Phi}{d \pi}>0$ for high $\pi$. Starting from high levels, a reduction in mortality initially increases the $\Phi$; however, the IWI eventually starts decreasing as mortality becomes low enough. The effect of a change in mortality on inequality of inheritance depends on the size of mortality. With lower mortality, accidental inheritance becomes less frequent but larger as voluntary savings increase. Thus, both the mean and variance of total bequests could increase or decrease depending on the exact values.

Finally, we summarize our findings in the following table, where a positive sign denotes an increase and a negative sign denotes a decrease in each indicator. 
Table 1: Summary of results: the effects of aging on indicators of inherited wealth

\begin{tabular}{|c|c|c|c|c|}
\hline & \multicolumn{2}{|c|}{ Declining fertility } & \multicolumn{2}{|c|}{ Increasing longevity } \\
\hline & With annuities & Without annuities & With annuities & Without annuities \\
\hline Inherited share of wealth (ISW) & - & - & - & - \\
\hline $\begin{array}{l}\text { Intentional inheritance to real } \\
\text { wage ratio (RIW-intentional) }\end{array}$ & - & - & - & No effect \\
\hline $\begin{array}{l}\text { Accidental inheritance to real } \\
\text { wage ratio (RIW-accidental) }\end{array}$ & + & + & + & No effect \\
\hline Inherited wealth inequality (IWI) & + & + & $+/-$ & $+/-$ \\
\hline
\end{tabular}

\section{Conclusion}

The purpose of this paper was to study the impact of aging, that is lower fertility and higher longevity, on the bequeathing decision and hence on the share of inheritance in capital accumulation. We also wanted to analyze the effect that the shift from defined benefits with annuities to defined contributions without annuities could have on the level of inherited wealth. We show that aging does not encourage bequeathing, whereas declining annuitization has a fostering effect on bequests, particularly on unplanned bequests.

On this point a caveat is in order. In this paper we have focused on two types of bequests, those relying on the absence of annuities and those arising from some joy of giving. In a companion paper (Onder and Pestieau, 2016b) we study other motives of bequeathing, such as pure altruism and preference for wealth. We show that declining fertility tends to foster altruistic bequests. As to the preference for wealth that characterizes top wealthy individuals, it is likely that its relative importance increases with the increasing concentration of wealth.

Our findings rest on a quite simple model comprising a number of simplifying assumptions. The strongest of them is undoubtedly the quasi-linearity of the utility function that assumes away income effects. This assumption could easily be replaced with a more standard utility function and another mechanism that would equalize inherited bequests at the start of any life-cycle. In the absence of either methods, we simply face insurmountable tractability problems and we can only conjecture about its incidence on our results. The effects that we observe in this paper would remain and should not a priori be neutralized by introducing heterogeneity in inherited bequests. Finally, our paper is of relevance even in countries where the u-shaped evolution of bequests is not observed. In these countries, aging would indeed explain the observed decrease in the share of inherited wealth in total wealth if the shifts in annuities as discussed in this paper are absent. 


\section{References}

[1] Andreoni, J. (1990), Impure Altruism and Donation of Public Goods: A Theory of Warm Glow Living, The Economic Journal 100(401):464-77.

[2] European Commission (2015) "The 2015 Ageing Report - Economic and Budgetary Projections for the 28 EU Member States (2013-2060)", European Economy 3/2015, Luxembourg: Publications Office of the European Union

[3] Kaplan, S. N. and Rauh, J, (2013) It's the market: The broad-based rise in the return to top talent. The Journal of Economic Perspectives, 27(3), 35-55.

[4] Lefebvre, M., P. Pestieau, and G. Ponthiere (2013) "Measuring poverty without the Mortality Paradox," Social Choice and Welfare, Springer, vol. 40(1), pages 285-316, January.

[5] Leroux, M-L, P. Pestieau and G. Ponthière, (2011) Longevity, Genes and Efforts: An Optimal Taxation Approach to Prevention, Journal of Health Economics, 30, 62-76,

[6] Munnell, A., J. Aubry and C. Crawford (2015) How has shift to defined contribution plans affectedsaving, Retirement Research, Number 15-16.

[7] Onder, H. and P. Pestieau (2016a) “Aging and the Inherited Wealth of Nations," CESifo DICE Report, Ifo Institute - Leibniz Institute for Economic Research at the University of Munich, vol. 14(1), pages 30-36, 05.

[8] Onder, H. and P. Pestieau (2016b) Aging and wealth transfers, unpublished

[9] Piketty T.,(2014), Capital in the 21st Century, Harvard University Press, Cambridge.

[10] Piketty, T. and G. Zucman, (2014a),Wealth and inheritance in the long run, in Handbook of Income Distribution North Holland, vol 2.

[11] Piketty, T. and G. Zucman, (2014b), Capital is back : wealth-income ratios in rich countries 1700-2010, Quarterly Journal of Economics, 1255-1310.

[12] Rognlie, M. (2015), Deciphering the fall and rise in the net capital share, BPEA Conference Draft.

[13] Weil, D. (1996) Intergenerational transfers, aging, and uncertainty, in Advances in the Economics of Aging Volume Author/Editor: David A. Wise, editor Volume Publisher: University of Chicago Press 
[14] Wolff, E. (2015) Changes in Household Wealth in the 1980s and 1990s in the U.S., , International Perspectives on Household Wealth, Elgar Publishing Ltd.

[15] Zhang, Junsen, Zhang, Jie and R. Lee, (2001), Mortality decline and long-run economic growth, Journal of Public Economics, Elsevier, vol. 80(3), 485-507 